\title{
Téoros
}

Revue de recherche en tourisme

\section{Une première}

\section{Normand Cazelais}

Volume 4, numéro 1, mars 1985

\section{L'information touristique}

URI : https://id.erudit.org/iderudit/1080733ar

DOI : https://doi.org/10.7202/1080733ar

Aller au sommaire du numéro

\section{Éditeur(s)}

Université du Québec à Montréal

\section{ISSN}

0712-8657 (imprimé)

1923-2705 (numérique)

Découvrir la revue

\section{Citer ce document}

Cazelais, N. (1985). Une première. Téoros, 4(1), 1-1.

https://doi.org/10.7202/1080733ar d'utilisation que vous pouvez consulter en ligne.

https://apropos.erudit.org/fr/usagers/politique-dutilisation/ 


\section{Présentation}

\section{Une première}

Dans la brève histoire de Téoros, ce numéro consacré à l'information touristique revêt un caractère bien spécial: en effet, la très grande partie des textes ont été ecrits par ses artisans. Sauf de rares exceptions, les auteurs sont des gens qui travaillent depuis de nombreuses années dans /'une ou l'autre des multiples sphères de l'information touristique.

C'est pourquoi les textes qui composent ce numéro, tout analytiques et descriptifs qu'ils puissent être, constituent d'abord des témoignages, des visions de l'intérieur. $\mathrm{Ce}$ recours aux expériences personnelles explique également l'absence presque totale de références à des études ou à des dossiers antérieurs: d'ailleurs, comme l'illustre éloquemment /'inventaire bibliographique dressé par le Centre d'études du tourisme, aucune analyse particulière ou générale, mis a part certains essais sur les guides touristiques, n'a été publiée à ce jour sur ce phénomène à la charnière de l'information et du tourisme. Ce numéro de Téoros fait donc office en quelque sorte de "première" en la matière.

Les différents aspects abordés dans les pages qui suivent traitent des diverses facettes de /'information touristique: I'information dite de destination s'adressant surtout au grand public, l'information spécialisée destinée aux intervenants touristiques de certaines sphères d"activités, l'information technique et scientifique, l'information corporative véhiculée par les organismes gouvernementaux et par les services de presse ou de relations publiques de certaines entreprises privées, les guides touristiques écrits. Y sont aussi abordés les caractéristiques particulières à ce type d'information, les problèmes (d'éthique notamment) qui lui sont inhérents, les structures d'organisation de production et de diffusion qui lui sont propres, les incidences politiques qui y sont reliees. Enfin, une transcription de la Déclaration de la Confédération latino-américaine des journalistes de tourisme (CLAPTUR) sur le tourisme en Amérique latine ( $L a$ Havane, octobre 1984), proche en ce sens de celle de la Féderation internationale des journalistes et écrivains de tourisme (FIJET), présente la nature des principes pouvant inspirer /'information touristique et l'action de ses agents.
Ce premier essai en est également un de réflexion sur les implications et conséquences de l'information tant sur le développement du tourisme que sur l'évolution des valeurs d'une société. D'autres avenues restent encore a analyser. Mais, comme disait Kipling, ceciest un autre histoire...

\section{Normand Cazelais}

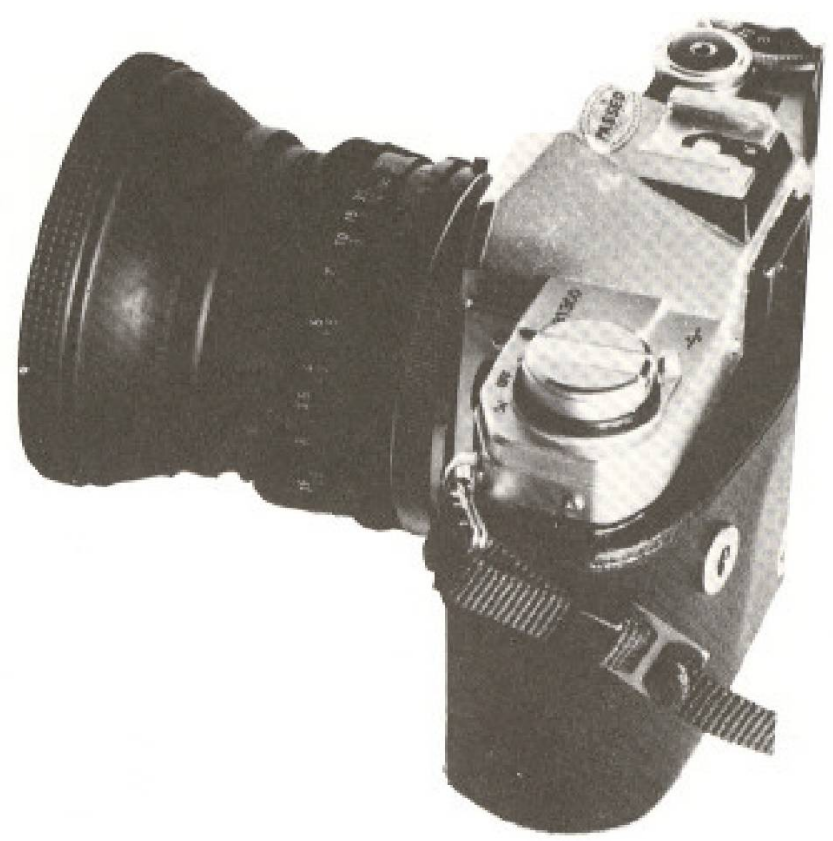

